\title{
Uterine Artery Embolization for a Safe Surgical Abortion in Human Very High-Order Multifetal Pregnancy: A Case Report
}

\author{
Federica Brosio ${ }^{*}$, Mizar Paragona1, Sabrina Pizzulo', Pascale Riu ${ }^{2}$, Daniela Valeriani1, \\ Giovanna Scassellati Sforzolini' ${ }^{1}$, Patrizia Logoteta ${ }^{3}$, Vittorio Unfer ${ }^{3}$ \\ ${ }^{1}$ Department of Obstetrics and Gynecology, San Camillo Forlanini Hospital, Rome, Italy \\ ${ }^{2}$ Department of Cardiological Science, San Camillo Forlanini Hospital, Rome, Italy \\ ${ }^{3}$ AGUNCO Obstetrics and Gynecology Centre, Rome, Italy \\ Email: federicabrosio@gmail.com
}

Received 8 October 2015; accepted 7 November 2015; published 10 November 2015

Copyright (C) 2015 by authors and Scientific Research Publishing Inc.

This work is licensed under the Creative Commons Attribution International License (CC BY).

http://creativecommons.org/licenses/by/4.0/

c) (i) Open Access

\begin{abstract}
In the last few decades, the use of ovarian stimulation with follicle stimulating hormone (FSH) or clomiphene citrate (CC) increases the percentage of multiple pregnancies. The presence of many follicles can lead to the risk of higher-order multiple pregnancy and ovarian high stimulation syndrome (OHSS). This is correlated to a significant increase in morbidity and mortality maternal and/or fetal rate. For this reason, sometime therapeutic measures are necessary to preserve woman's health. We describe the case of a surgical abortion using a transcatheter arterial embolization (TAE), a minimally invasive, safe and effective procedure to preserve the patients.
\end{abstract}

\section{Keywords}

Multiple Pregnancies, Transcatheter Arterial Embolization, Abortion, Pelvic Hemorrhage

\section{Introduction}

The incidence of multifetal pregnancies has increased up to the last few decades, especially when linked to the use of assisted reproduction techniques (ART). The intrauterine insemination (IUI) with or without ovarian stimulation is commonly used in the treatment of infertility. The European IVF monitoring program reported al-

\footnotetext{
${ }^{*}$ Corresponding author.
}

How to cite this paper: Brosio, F., Paragona, M., Pizzulo, S., Riu, P., Valeriani, D., Sforzolini, G.S., Logoteta, P. and Unfer, V. (2015) Uterine Artery Embolization for a Safe Surgical Abortion in Human Very High-Order Multifetal Pregnancy: A Case Report. Open Journal of Obstetrics and Gynecology, 5, 735-739. http://dx.doi.org/10.4236/ojog.2015.513103 
ready in 2004 a pregnancy rate of $12.3 \%$ per cycle of IUI, with $87 \%$ of the total cases being single pregnancies, and the remaining $13 \%$ multiple pregnancies [1] [2].

The use of ovarian stimulation with follicle stimulating hormone (FSH) or clomiphene citrate (CC) has increased the percentage of multiple pregnancies, which to date ranges from $10 \%$ to $40 \%$ without large relative variations over the years, as reported in more recent studies [3].

A correlation between follicle number and multiple pregnancy has been confirmed in all studies. Namely the higher-order multiple pregnancy rate was over $50 \%$ when nine or more follicles beyond $10 \mathrm{~mm}$ in diameter were present. A cycle involving the development of many follicles carries the risk of higher-order multiple pregnancy and ovarian high stimulation syndrome (OHSS) and should be cancelled. This is associated to a significant increase in morbidity and mortality maternal and/or fetal rate, in direct proportion to the number of fetuses [4] and spurred the necessity of the development of techniques for embryo/fetal reduction to improve maternal and perinatal outcomes [5]. The 2006 FIGO Committee Report stated that "multiple pregnancy of an order of magnitude higher than twins involves great danger for the woman's health and also for her fetuses... It may be considered ethically preferable to reduce the number of fetuses rather than to do nothing” [6].

\section{Case Report}

A 34 years old patient showed up for counseling to our institution with a very high order multifetal pregnancy to 8 weeks. The patient with primary infertility has been treated in an ART center with ovarian stimulation (FSH), and 36 hours later hCG administration, IUI of capacitated sperm from her partner.

Two weeks later she was admitted with OHSS and stayed in hospital for 5 days. Ultrasound scan on the seventh week revealed six intrauterine viable gestational sac. The next ultrasound on the 8th weeks showed the presence of one gestational sac without an embryo or yolk sac and 10 gestational sacs each containing an embryo with cardiac activity (Figure 1). The ultrasonographic measurement of the crown-rump length (CRL) was defined for each pregnancies $(20 \mathrm{~mm})$ accordingly to the period of amenorrhea. Multifetal reduction was advised in order to decrease of the maternal morbidity-incompatibility of a very high order multifetal pregnancy for the human species. The couple rejected embryo reduction and opted instead for interruption of the pregnancy.

A through counselling has been performed, aimed at providing the couple an informed overview on the risks related procedure of vacuum aspiration in a multiple pregnancy with 10 embryos, with some ectopic location (interstitial and near tubal). A further medical consultation by interventional radiology has been performed, than a full staff decision was taken to perform a selective preventive embolization of the uterine arteries by absorbable material in order to reduce the risk of bleeding and life threatening maternal hemorrhage related intervention.

Hospitalization has hence been set up. The TAE was performed under conscious antalgic sedation, selectively in uterine artery with absorbable material (gelatin sponge particles) resulting in a reduction of flow (Figure 2). Surgery (vacuum aspiration) was performed 24 hours later after administration of 400 mcg of misoprostol. No complication was recorded. The post-surgery course result in rule and the patient was discharged on the following day. Remote control of 15 days was the framework ultrasound in rule (Figure 3).
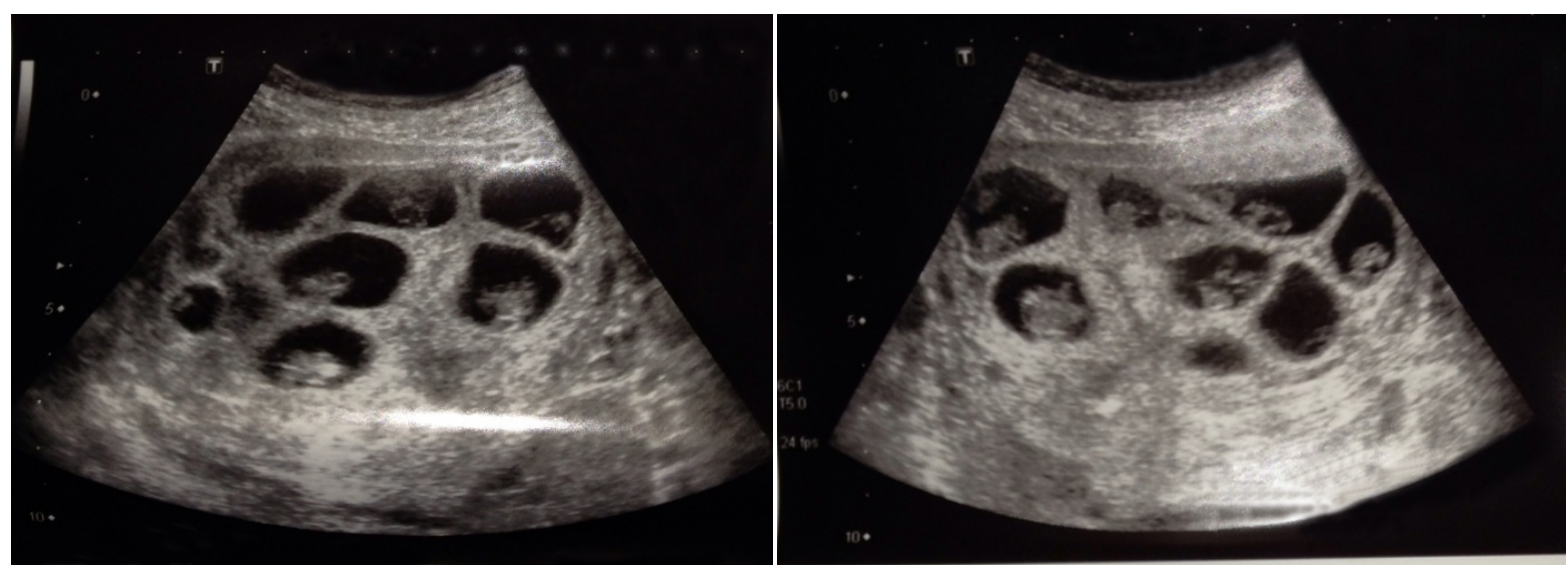

Figure 1. Transvaginal ultrasounds after eight weeks. The two figures show the presence of 10 gestational sacs containing embryo with cardiac activity. 


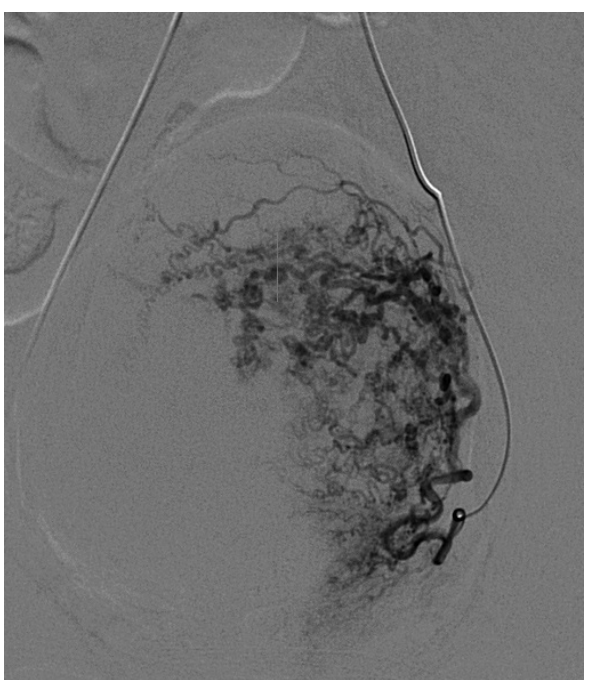

(a)

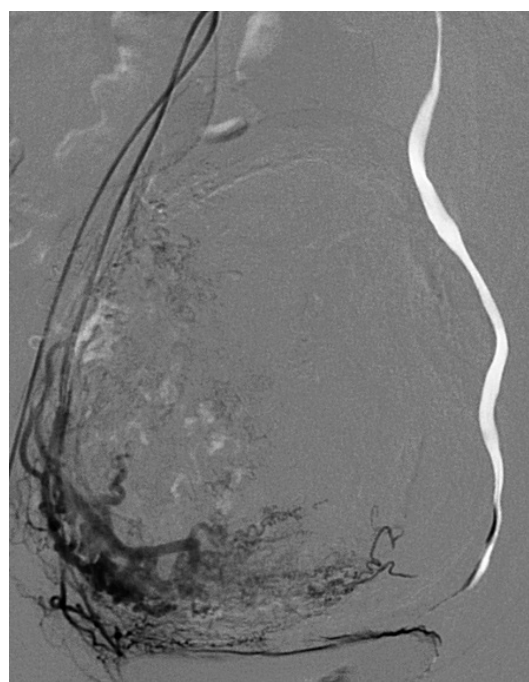

(b)

Figure 2. Selective catheterization of left (a) and right (b) uterine arteries.

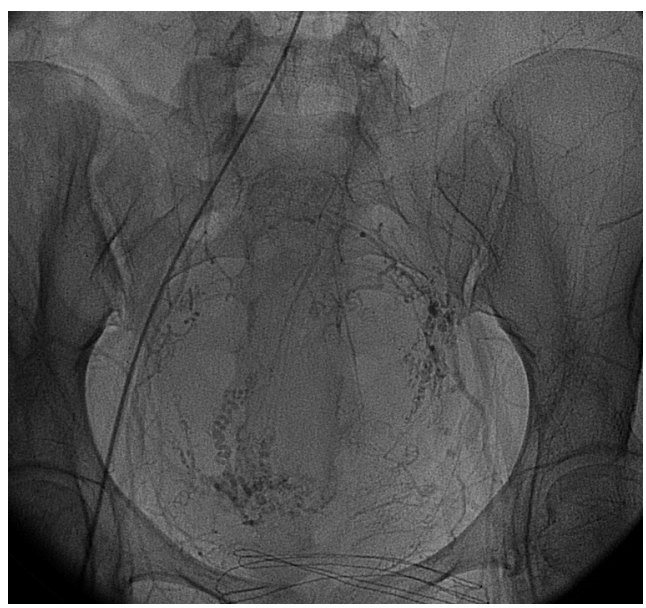

Figure 3. Panoramic view after transcatheter arterial embolization (TAE).

\section{Discussion}

Management of pelvic hemorrhage represents an issue of critical concern to obstetricians and gynecologists. Therapeutic measures in case of bleeding provide a first step with the conservative measure as administration of uterotonic drugs, curettage for retained products, bimanual uterine massage, uterine balloon tamponade and if not proven adequate and sufficient in dealing with the hemorrhagy-second surgical step with bilateral hypogastric artery or uterine artery ligation. If bleeding persists, a surgical hysterectomy as a lifesaving measure is required, although this determines the permanent loss of fertility [7] [8].

Transcatheter arterial embolization (TAE) is a minimally invasive procedures, safe and effective, performed under local anesthesia in order to control for genital bleeding. The use of diagnostic angiography for the acute hemorrhage was initially validated in the 1960 [9]. Over seventy years ago this method was used to control gastrointestinal hemorrhage, in the past twenty years it has been employed to control gynecological and obstetric hemorrhage. TAE is now a well-accepted procedure for the management of post-partum bleeding, for the hemorrhage from ectopic pregnancy, abdominal pregnancies and cervical ectopic pregnancies, for the post-surgical bleeding, for the trauma related hemorrhage, and for prophylactic uses of embolotherapy in patients at high risk of bleeding [10] [11]. Several studies highlight the advantages of using the TAE as a prophylactic measure in ectopic pregnancy [12], uterine leiomyomas, placenta previa, placenta accreta, fetal death, especially in the 
presence of coagulation derangement. The main advantages of TAE in preventive embolization is the possibility of conservative management (without bleeding), avoiding emergency surgery for hemorrhage with vascular ligation of hystercetomy. Furthermore this strategy provides reduction of the risks associated a surgical procedures, fertility preservation, shorter hospitalization.

TAE, as a prophylactic measure in our patient, followed by immediate evacuation of pregnancy effectively terminates a viable gestation with minimal blood loss while maintaining fertility capacity. Complications of TAE are rare, approximately 3\% - 5\%. The minor potential complications of TAE include hematoma or infectious complications at the puncture site, dissection of the canulated artery, transient sciatic nerve paresis with buttock numbness, and synechias. The technique could lead to a reduction in fertility through reduction of ovarian reserve and sexuality due to interference with blood supply to the clitoris, cervix and uterus. However many studies reported pregnancies and properly completed after temporary embolization of the uterine arteries, regardless of the cause [13]. Major complications such as uterine necrosis requiring hysterectomy or non-target embolization are extremely rare. Absorbable properties of gelatin sponge particles reduce the risk of adverse effect.

\section{Conclusion}

A prophylactic embolization of uterine artery seems to be a safe and effective procedure to avoid vaginal bleeding and can be considered as conservative management for patients at high risk of bleeding who desire to preserve their fertility.

\section{References}

[1] Dunn, A. and Macfarlane, A. (1996) Recent Trends in the Incidence of Multiple Births and Associated Mortality in England and Wales. Archives of Disease in Childhood, 75, F10-F19. http://dx.doi.org/10.1136/fn.75.1.f10

[2] Andersen, A.N., Goossens, V., Ferraretti, A.P., Bhattacharya, S., Felberbaum, R., de Mouzon, J. and Nygren, K.G. (2008) The European IVF-Monitoring (EIM) Consortium, for the European Society of Human Reproduction Embryology (ESHRE). Assisted Reproductive Technology in Europe, 2004: Results Generated from European Registers by ESHRE. Human Reproduction, 23, 756-771. http://dx.doi.org/10.1093/humrep/den014

[3] Fauser, B.C.J.M., Devroey, P. and Macklon, N.S. (2005) Multiple Birth Resulting from Ovarian Stimulation for Subfertility Treatment. Lancet, 365, 1807-1816. http://dx.doi.org/10.1016/S0140-6736(05)66478-1

[4] Gonen, R., Heyman, E., Elizabeth, V., Asztalos, E.V., Oslsson, A., Pitson, L.C., Shennan, A.T. and Milligan, J.E. (1990) The Outcome of Triplet, Quadruplet, and Quintuplet Pregnancies Managed in a Perinatal Unit: Obstetric, Neonatal, and Follow-Up Data. American Journal of Obstetrics \& Gynecology, 162, 454-459. http://dx.doi.org/10.1016/0002-9378(90)90407-X

[5] Cheong, M.A. and Tay, C.S.K. (2014) Application of Legal Principles and Medical Ethics: Multifetal Pregnancy and Fetal Reduction. Singapore Medical Journal, 55, 298-301. http://dx.doi.org/10.11622/smedj.2014077

[6] FIGO Committee for the Ethical Aspects of Human Reproduction and Women's Health (2006) Ethical Recommendations on Multiple Pregnancy and Multifetal Reduction. FIGO Committee for the Ethical Aspects of Human Reproduction and Women's Health. International Journal of Gynecology \& Obstetrics, 92, 331-332. http://dx.doi.org/10.1016/j.ijgo.2005.12.019

[7] Sheldon, W., Blum, J., Vogel, J., Souza, J., Gulmezoglu, A. and Winikoff, B. (2014) WHO Multicountry Survey on Maternal and Newborn Health Research Network. Postpartum Haemorrhage Management, Risks, and Maternal Outcomes: Findings from the World Health Organization Multicountry Survey on Maternal and Newborn Health. BJOG, 121, 5-13. http://dx.doi.org/10.1111/1471-0528.12636

[8] Wright, C.E., Chauhan, S.P. and Abuhamad, A.Z. (2014) Bakriballoon in the Management of Postpartum Hemorrhage: A Review. American Journal of Perinatology, 31, 957-964. http://dx.doi.org/10.1055/s-0034-1372422

[9] Baum, S., Nusbaum, M., Clearfield, H.R., Kuroda, K. and Tumen, H.J. (1967) Angiography in the Diagnosis of Gastrointestinal Bleeding. Archives of Internal Medicine, 119, 16-24. http://dx.doi.org/10.1001/archinte.1967.00290190064003

[10] Martin Jr., J.N., Ridgway, L.E., Connors, J.J., Sessums, J.K., Martin, R.W. and Morrison, J.C. (1990) Angiographic Arterial Embolization and Computed Tomography-Directed Drainage for the Management of Hemorrhage and Infection with Abdominal Pregnancy. Obstetrics \& Gynecology, 76, 941-945.

[11] Singhal, S., Singh, A., Raghunandan, C., Gupta, U. and Dutt, S. (2014) Uterine Artery Embolization: Exploring New Dimensions in Obstetric Emergencies. Oman Medical Journal, 29, 217-221. http://dx.doi.org/10.5001/omj.2014.53

[12] Frates, M.C., Benson, C.B., Doubilet, P.M., Di Salvo, D.N., Brown, D.L., Laing, F.C., Rein, M.S. and Osathanondh, R. 
(1994) Cervical Ectopic Pregnancy: Results of Conservative Treatment. Radiology, 191, 773-775. http://dx.doi.org/10.1148/radiology.191.3.8184062

[13] Krissi, H., Hiersch, L., Stolovitch, N., Nitke, S., Wiznitzer, A. and Peled, Y. (2014) Outcome, Complications and Future Fertility in Women Treated with Uterine Artery Embolization and Methotrexate for Non-Tubal Ectopic Pregnancy. European Journal of Obstetrics \& Gynecology and Reproductive Biology, 182, 172-176. http://dx.doi.org/10.1016/j.ejogrb.2014.09.026 